\title{
An Exploratory Study on The Influence of Color on Appetite Sensation in a Dining Environment
}

\author{
Chui Shan, KONG
}

\begin{abstract}
-
Color plays an important role in psychology and human behavior. It should not be ignored in business marketing. The purpose of this study is to examine the relationship between color in a dining environment and appetite sensation. Furthermore, one of the controversial problems in color psychology, the gender difference, had also been discussed in this study. To study that, data were collected from the subjects who viewed eight color tuned 360-degree photos in the headset during a sensory evaluation test. Result from 50 subjects showed that black, white, red and yellow were the appetitive colors, while green was the opposite. Besides this, there was no significant difference in gender. As an exploratory study, it provides an additional insight into how color in a dining environment influences customer's appetite and further direction in academia.
\end{abstract}

Keywords-Color Perception, Appetite Sensation, Dining Environment

\section{Introduction}

High quality of food and service are believed to be essential for the success of a restaurant; ambience is equally essential. In fact, people, in their decision making, pay attention more on intangible products, i.e. atmosphere, ambience and environment, than on tangible products, goods and service (Kotler 1973; Robert \& John, 1982; Ryu \& Han, 2011). In dining environment, commercial dining space was coined "atmosphere" in marketing by Philip Kotler (1973). In addition, customers can be fostered and sustained by environment in a restaurant (Donovan et al., 1994; Sherman et al., 1997).

Among all variables, adjusting the color is the easiest way to change the interior environment and ambience (Jalil et al., 2012). Most research studies about restaurant environment aimed to provide a better understanding on customer behavior. Nevertheless, there were only few studies discussing the impact of environment on appetite, though appetite is the basic desire of human being (Maslow, 1943).

In theory, the findings of this exploratory research study provided additional insights into how color in dining environment influences customer's appetite. Practically speaking, it addressed questions of potential rationales and consequences of environment designing in visual merchandising. The objectives of this study were (1) to examine the relationship of perceived appropriateness between color of dining environment and appetite sensation; and (2) to evaluate if gender has impact on the color choice of dining environment on appetite sensation.

\section{Literature Review}

\section{A. Physical Environment}

Physical environment, which also called as servicescape, was a complex mix of different objective physical factors. Ryu and Han (2011) described dining environment as "manmade physical environment" that different environment dimensions could be changed and adjusted by human. As customers cannot lean on food quality and service before they experience, they judge what a restaurant would afford from the physical setting. Moreover, it is proved that the environment can affect emotional feelings and pleasure in the service area (Ryu and Han, 2011). Meharbian and Russel (1974) suggested that dining environment evoked customer emotion and these emotional states affected human behavior. The Stimulus-Organism-Response mode (S-O-R model), which explains how customers behavior reacts to the environment, refers to external factors influencing customer's internal factors.

To examine how color as the external factors in environment (S) influence people appetite $(\mathrm{O})$, which is placed as the emotional state, the idea of S-O-R framework was adopted in this study (see Fig. 1).

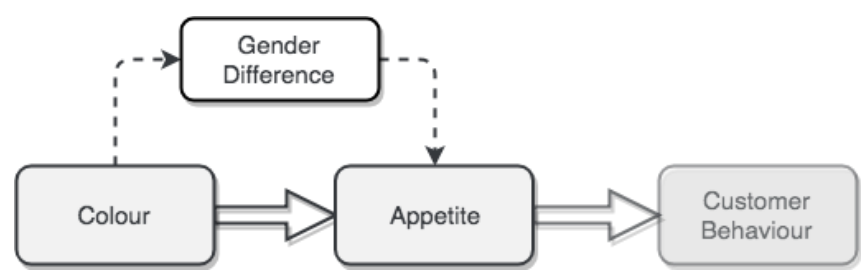

Figure 1. Proposed Simulus-Organism-Response (S-O-R) Franework

\section{B. Color}

It seems normal that we can see color in the world, but what is color exactly? The perceptions on the matter are quite different. There is no color in physical form. The lightwaves in different wavelengths can be distinguished by human eyes, which make color be "seen" in human brain (Hunt, 2004). The effect is happening in our mind, in which a stimuli can be processed subjectively (Winkielman, Schwarz, Reber \& Fazendeiro, 2000).

\section{1) Color Psychology}

Symbolization of colors triggers recollection of unconscious and subconscious memories. Over the years, the relationships between colors and human civilization are inseparable (Aslam, 2006; Birren, 1950; Magoulas, 2009; Valdez \& Mehrabian, 1994). Whitfield and Slatter (1978) proved that the placement of certain colors has psychological impact on the space and environment, especially in interior design. Bellizzi, Crowley and Hasty 
Proc. of The Eighth Intl. Conf. On Advances In Economics, Social Science and Human Behaviour Study - ESSHBS 2018 Copyright (c) Institute of Research Engineers and Doctors, USA. All rights reserved.

ISBN: 978-1-63248-156-6 doi: 10.15224/978-1-63248-156-6-17

(1983) further stated that color could affect the emotion and feeling. Mahnke \& Mahnke, (1947) also pointed out that the effect of hue on physical environment were based on the material, texture, and duration, which brought up a deeper question of defining psychological effect associated with color and experience.

\section{2) Gender Difference}

There have been several research studies investigating the gender difference in responding to color. According to Stappenbeld (2012), female notices the color and environment of shop more than male, though female is less affected by color than male. Further studies by Guilford and Smith (1959) concluded that male was more tolerant of achromatic colors, such as black, grey and white, while female had more color conscious than male. It also stated that female had more flexible and diverse taste towards color. However, Whitfield and Whiltshire (1990) disagreed to that. As there were so many differences in that from various studies, they stated that color preference was not affected by age and gender. It also pointed out that earlier studies tended to use limited stimulus sets, which failed to control the value and saturation of color.

\section{Appetite}

Appetite is controlled and affected by numerous factors, such as hormonal signals from human body. The signals will go through emotional and cognitive thinking process which is the cue of hunger and fullness. In Maslow's hierarchy of needs, "Physiological needs", including hunger, are defined as the basic needs of human being (Maslow, 1943). To classify, there are differences between hunger and appetite. Hunger is the need of eat, while appetite is the desire to eat (Lowe \& Butryn, 2007; Reiss, 2004). Satter (2007) developed Satter's hierarchy of food needs by applying Maslow's hierarchy of needs to demonstrated the need of food into food management and nutrition.

\section{1) Appetite Sensation}

Appetite level was related to appetite sensation and personal emotion level, such as stress level (Epel et al., 2001). Past literature proved that appetite could be influenced by a number of factors. In term of gender, female has greater appetite than male, while appetite decreases with age (Gregersen et al., 2011). Nevertheless, Painchaud and others (2016) declared that body mass index (BMI), weight and restrained eating did not have a significant relation with appetite. Flint (2000) proved that the ranking of postconsumption rating was usually deducted.

\section{2) Color on Appetite}

Color is one of the elements in visual merchandising, in which human emotion was related and associated. It specified that reddish or yellowish light excited huger, while blue and green light had opposite response. Despite the findings of the research, Birren (1963) stated that the placement of color involves personal and emotion interpretations, that there is no absolute answer of how people feel towards a color. Based on Fig. 2, he suggested that warm and bright color for background of food service would encourage the appetite level.

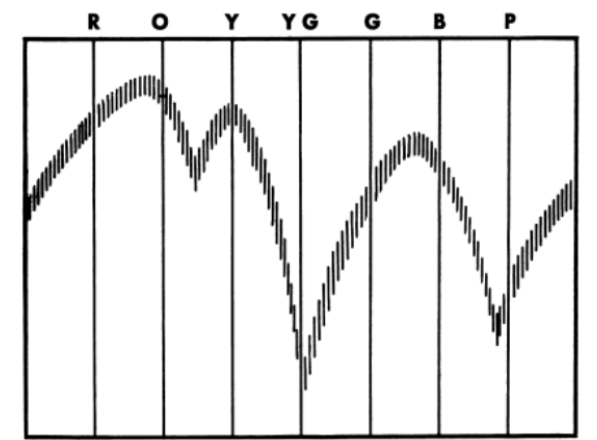

Figure 2. Approach of Color to Appetite (Birren, 1963)

\section{Methodology}

This study was carried out with the cooperation of 50 volunteers as subjects (participants) and 5 volunteers as respondents in pilot test. To collect the data on convenience sampling, the participants were selected randomly from the undergraduate students of the Technology and Higher Education Institute of Hong Kong (THEi). The quantitatve method of collecting data was a sensory evaluation test with questionniare and virtual reality (VR).

Before the subjects took the tests, they have taken the Ishihara's test for color blindness compulsorily (Ishihara, 1975). Since this study was to find out the relationship between color and appetite sensation, subjects who were color-blind were rejected to take the test. To show the color clearly, Hue-Saturation-Value (HSV) model was adopted in this study (Foley, 1995; Joblove \& Greenberg 1978). For the HSV model, eight colors (Red, Green, Blue, Cyan, Magenta, Yellow, Black, White) (see Fig. 3), which are represents primary and secondary colors of the color wheel.

\section{A. Colour tuned Photos}

To maximize the quality of the images, 360-degree camrea and VR headset, which could generate realistic images simulating imaginary 3-dimensional environments, were adopted in this study. To simulate a controlled and realistic environment to the subjects, no music would be played and room temperature was controlled within the range of $23^{\circ} \mathrm{C}-24^{\circ} \mathrm{C}$. Only the sight of subjects was examined in this study, which could intensify reliability of the data. For controlled variable setting, the test was taken between 2:30p.m. and 5:30p.m., which was Hong Kong's afternoon tea time, at which the desire of eat was easier to determine (Tam, 1997).

\section{B. Instruments}

To measure the correct positive or negative feeling responses from the subjects, Visual Analogue Scale (VAS), which is a psychometric rating scale similar to Likert scale, was used as a rating scale in the questionnaire during the sensory evaluation test. In this study, the two extreme points were "I am feeling HUNGRY" and "I am feeling of FULLNESS", which were also known as the extreme wordings in desire of eat in appetite sensation (Reiss, 2004). To collect accurate answers, no colour wordings were shown on any materials that the subjects would receive 
Proc. of The Eighth Intl. Conf. On Advances In Economics, Social Science and Human Behaviour Study - ESSHBS 2018 Copyright (c) Institute of Research Engineers and Doctors, USA. All rights reserved.

ISBN: 978-1-63248-156-6 doi: 10.15224/978-1-63248-156-6-17

during the sensory evaluation tests. In the questionnaire, "first, second, third......eighth" were used instead.

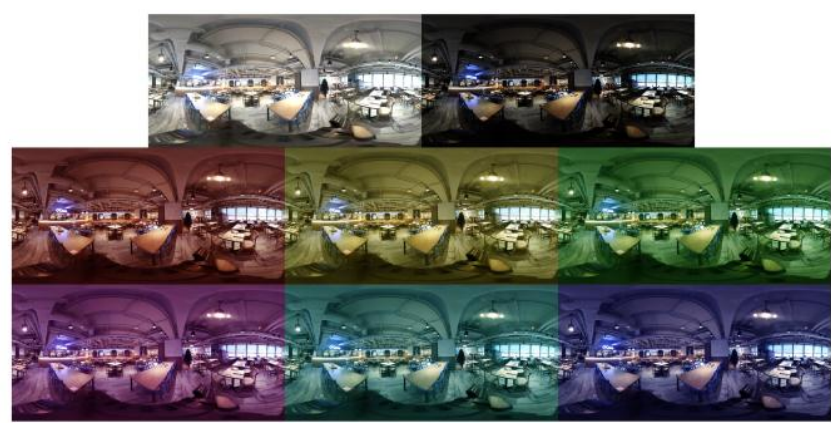

Figure 3. Color Tuned Images

\section{Iv. Findings}

Once all the sensory evaluation tests and questionnaire completed, the data were analysed in statistics way by using a software called, IBM SPSS Statsitics. Descrptive statsicis and One-way multivariate analysis of variance (One-way MANOVA) were used to show the data in statistc way and to find out whether there was siginificant difference or not bewteen gender.

\section{A. Color Perception}

\section{Objective 1:}

the relationship of perceived appropriateness between color of dining environment and appetite sensation

Eight colors were studied with a VAS scale. In the scale, the highest point, seven (7), represented the subjects feeling "hungry" or "have desire to eat", which was considered as having appetite. The lowest point, one (1), represented the subjects feeling "fullness" or "do not have desire to eat", which was considered as not having appetite. The overall descriptive statistics of the test were shown in Table I below, displaying in a descending order of sums and mean scores. Results showed that the mean score of black (5.52) was the highest, followed by that of white (5.38), yellow (5.04) and red (4.96). In the contrast, magenta (3.14) got the second lowest mean score, while green (1.86) got the lowest mean score. The difference between the highest and the lowest mean scores was 3.66. Besides, the vast majority of colors got extreme answers, except one color, green, that the maximum score of green was 4 . sentence.
TABLE I. OVERALl DESCRPTIVE Statistics

\begin{tabular}{ll|r|r|r|r|r} 
& $\mathrm{N}$ & Minimum & Maximum & Sum & Mean & Std. Deviation \\
\hline Black & 50 & 1 & 7 & 276 & 5.52 & 1.282 \\
\hline White & 50 & 1 & 7 & 269 & 5.38 & 1.244 \\
\hline Yellow & 50 & 1 & 7 & 252 & 5.04 & 1.384 \\
\hline Red & 50 & 2 & 7 & 248 & 4.96 & 1.228 \\
\hline Blue & 50 & 2 & 6 & 197 & 3.94 & 1.268 \\
\hline Cyan & 50 & 1 & 7 & 176 & 3.52 & 1.374 \\
\hline Magenta & 50 & 1 & 6 & 157 & 3.14 & 1.340 \\
\hline Green & 50 & 1 & 4 & 93 & 1.86 & .969 \\
\hline
\end{tabular}

\section{B. Gender}

To determine if significant difference exists between two or more than two different variables, one-way MANOVA was used in the following. If $p$-value is $<0.0005$, significant difference is defined in that variable or category. A test using one-way MANOVA was carried out to find out whether there was any difference between genders (female \& male).

\section{Objective 2:}

Gender has impact on the color choice on appetite sensation

The one-way MANOVA to find out whether there was any difference between different genders (female \& male). The null hypotheses and alternative hypotheses of each color were:

$\mathbf{H}_{\mathbf{0}}$ : There is no significant difference between genders in colors on appetite sensation

$\mathbf{H}_{1}$ : There is significant difference between genders in colors on appetite sensation.

The results are shown in Table II below. To find out whether there is significant difference, the second effect, labelled in "Gender", Wilks' Lambda row should be looked at. The sig. value is 0.263 , which is greater than 0.0005 . Therefore, there is no significant difference between genders in colors on appetite sensation, $\mathrm{F}(8,41)=1.32$, $\mathrm{p}>.0005$; Wilk's $\Lambda=0.796$, partial $\eta 2=.20$.

TABLE II. Multivariate Tests' Results of Gender Difference

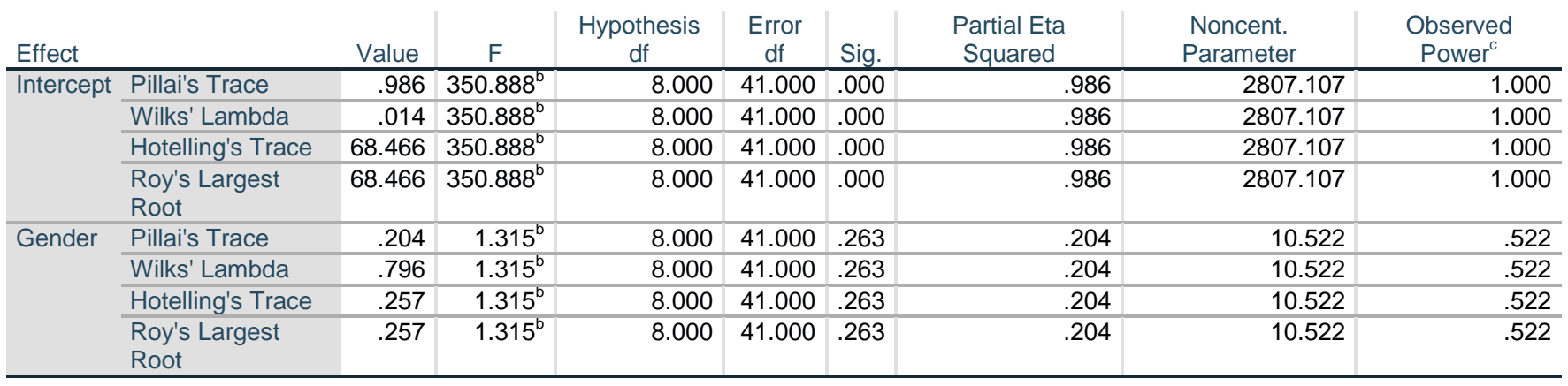


Proc. of The Eighth Intl. Conf. On Advances In Economics, Social Science and Human Behaviour Study - ESSHBS 2018 Copyright (c) Institute of Research Engineers and Doctors, USA. All rights reserved. ISBN: 978-1-63248-156-6 doi: 10.15224/978-1-63248-156-6-17

\section{Education Background}

Although it was not one of the objectives of current study, the data of education background related to colour and appetite sensation were examined too. The one-way MANOVA to find out whether there was any difference among different faculties' students, including the Faculty of Design and Environment, the Faculty of Management and Hospitality, and the Faculty of Science and Technology. The null hypothesis and alternative hypothesis were:

$\mathbf{H}_{\mathbf{0}}$ : There is no significant difference among the faculties in colours on appetite sensation.
$\mathbf{H}_{1}$ : There is significant difference among the faculties in colours on appetite sensation.

The result from SPSS are shown in Table III below. To find out whether there is significant difference, the second effect, labelled in "Faculties", Wilks' Lambda row should be looked at. The sig. value is 0.013 , which is greater than 0.0005 . Therefore, there is no significant difference among the faculties in colours on appetite sensation, $\mathrm{F}(16,80)=$ $2.17, \mathrm{p}>.0005$; Wilk's $\Lambda=0.486$, partial $\eta 2=.30$

TABLE III. Multivariate Tests' Results of Difference in EdUCATIONA BaCkground (Faculties)

\begin{tabular}{|c|c|c|c|c|c|c|c|c|c|}
\hline & Effect & Value & $\mathrm{F}$ & $\begin{array}{c}\text { Hypothesis } \\
\text { df }\end{array}$ & Error df & Sig. & $\begin{array}{l}\text { Partial Eta } \\
\text { Squared }\end{array}$ & $\begin{array}{l}\text { Noncent. } \\
\text { Parameter }\end{array}$ & $\begin{array}{c}\text { Observed } \\
\text { Power }^{d}\end{array}$ \\
\hline \multirow[t]{4}{*}{ Intercept } & Pillai's Trace & .985 & $334.418^{b}$ & 8.000 & 40.000 & .000 & .985 & 2675.340 & 1.000 \\
\hline & Wilks' Lambda & .015 & $334.418^{b}$ & 8.000 & 40.000 & .000 & .985 & 2675.340 & 1.000 \\
\hline & Hotelling's Trace & 66.884 & $334.418^{b}$ & 8.000 & 40.000 & .000 & .985 & 2675.340 & 1.000 \\
\hline & Roy's Largest Root & 66.884 & $334.418^{b}$ & 8.000 & 40.000 & .000 & .985 & 2675.340 & 1.000 \\
\hline \multirow[t]{4}{*}{ Faculty } & Pillai's Trace & .581 & 2.096 & 16.000 & 82.000 & .016 & 290 & 33.534 & .953 \\
\hline & Wilks' Lambda & 486 & $2.170^{\mathrm{b}}$ & 16.000 & 80.000 & .013 & .303 & 34.724 & .960 \\
\hline & Hotelling's Trace & .919 & 2.241 & 16.000 & 78.000 & .010 & .315 & 35.848 & .965 \\
\hline & Roy's Largest Root & .731 & $3.749^{c}$ & 8.000 & 41.000 & .002 & .422 & 29.991 & .968 \\
\hline
\end{tabular}

\section{v. Discussion}

\section{A. Color Preception}

The colors, black, white, red and yellow, pointed out that they could stimulate the subjects feeling hungry and the desire to eat. Based on the test, the mean score of all colors was 4.17 and the black, white, red and yellow got scores higher than the mean, while green got the lowest score (see Fig. 4).

Similar to Birren (1963), warm colors (red and yellow) were proved to increase subjects' appetite level, while green discouraged that. The data mostly were collected from ethnic Chinese; similar results were found in a study America (Birren, 1963). Based on looking at two findings, a conjecture formed, that "red and yellow color are appetitive color".

Unexpectedly, achromatic colors (white and black) got the highest mean scores in the test. This result completely overthrew the theory proposed by Mahnke and Mahnke (1947) that achromatic colors were considered as boring and not attractive in indoor space. After all, color in dining environment was proven to have impact on appetite sensation in this study.

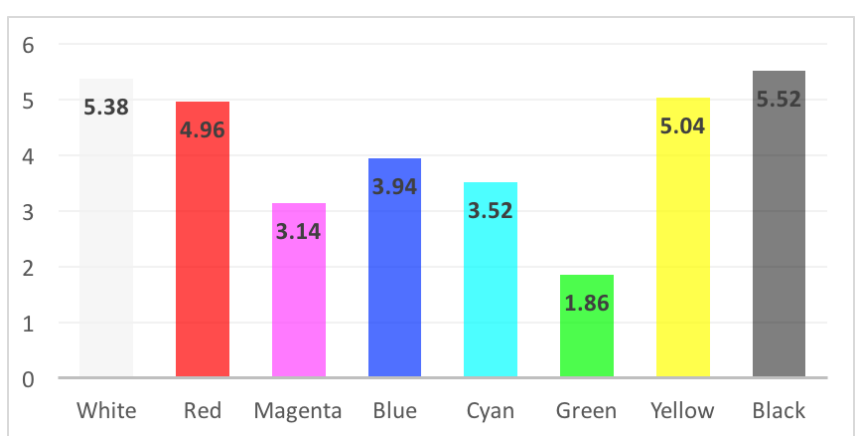

Figure 4. Graph of Mean Scores

\section{B. Gender Difference}

Results from one-way MANOVA showed that there was no significant difference between genders. It verified what Whitfield and Whilshire (1990) thought that the color preference was not affected by gender.

However, there was an interesting outcome when the data were presented as line graph (see Fig. 5). The colors which had high mean scores (white, red, yellow, black) got higher scores from female subjects than male subjects. In addition, the colors which had low mean scores (magenta, blue, green) got lower scores from female subjects than male subjects. It was a circumstantial evidence to back up the theory suggested by Guilford and Smith (1964) that female had more flexible and diverse taste towards color. Nevertheless, the statistic result stated that there was no significant difference between genders. So, this conjecture was not accepted in this study.

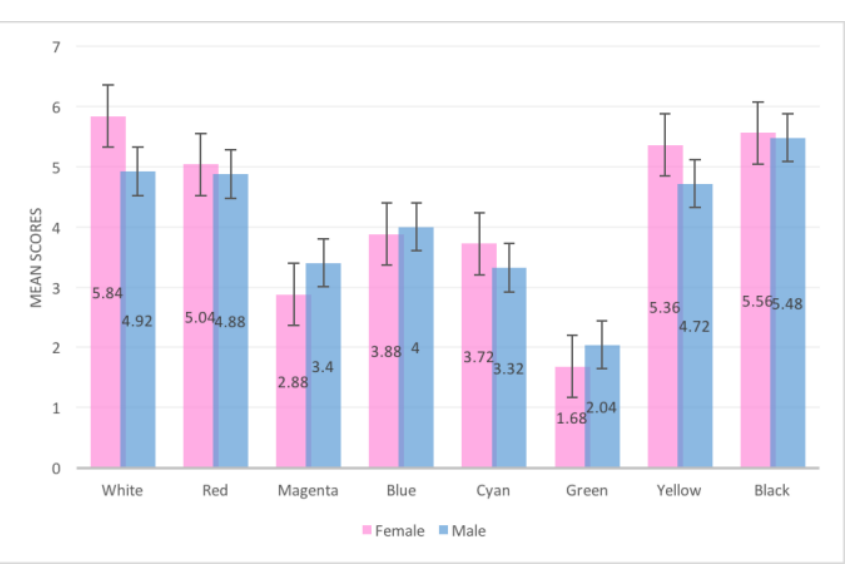

Figure 5. Graph of Mean Scores with Gender Difference 


\section{Personal Background}

There was no significant difference in colour on appetite sensation among the faculties from which the students came. Although colours could be symbols and contained meanings (Aslam, 2006; Magoulas 2009), it did not have impact on appetite sensation, in terms of attractiveness, hunger and fullness. Further investigation by using other scientific method is recommended, as the data were collecteds in subjective way, while "objective" results through observation might have different outcomes.

Despite the limitation of the sample size, that the data mostly were collected from ethnic Chinese, similar results were found in a study America (Birren, 1963). That study stated that warm colour, (red, orange and yellow) were the appetitive colour, while red and yellow colour were found as appetite colour in current study. Based on looking at two findings, a conjecture formed, that "red and yellow colour are appetitive colour".

\section{vi. Conclusion}

This exploratory study provides an additional insight on how colors in dining environment have impact on appetite sensation. This exploratory study proves that colors had impact on appetite sensation, while there is no significant difference between genders. It should acknowledge that the discussion of the findings can only be generalized to specific population, while the extension of applicability of the major finding of this study is limited.

\section{vII. Contribution}

\section{A. Visual Marketing}

Aslam (2006) pointed out that colours were the most powerful elements in marketing. Colour for the environment could help people recognize and pay attentions on that. Current study suggested that achromatic colours (white and black) and warm colours (red and yellow) were the most appetitive colours in dining environment. It explains why most colour tones in restaurant were warm colours with different brightness, while cool colours were seldom used. Yet, Adjustments and modifications are required, if service providers want to apply the theory in practical situation.

\section{B. Restaurant}

High quality of food and service are believed to be essential for the success of a restaurant; ambience is equally essential. The trends of the industry change from time to time. If restaurant service providers and designers want to gain the attention of the public and target customers, unique dining experience with high satisfaction are required. As dining environment change can affect customer's appetite sensation, re-designing the interior design of dining environment can achieve preferable situation.

\section{1) Colour Tone}

Black, white, red and yellow, which were found as appetitive colour, is suggested as the main colour tone. Not only the colour tone of the interior design of the celling and wall, designers should also consider changing the ambience lighting. Brightness is not the only option of tuning the lighting system, hue and saturation also can be adjusted because of the modern technology launched recent year, colour tuned light-emitting diode (LED) lighting systems.

\section{2) Modern Technology}

Dining out is a sensory experience, so the new technologies are started to be used in the restaurant to raise dining experience of the customers. In this study, it proved that VR headset can simulate a dining environment. In recent years, some restaurants invested virtual and augmented reality (VR and $\mathrm{AR}$ ) to provide a unique and unexpected dining experience.

As the costs of these kind of technology are getting lower, it makes sense that these technologies are adopted in restaurants. To enhance the dining experience in this technology era, investment of modern and innovation technology will become a trend in the future.

\section{Academia}

By looking to the existing literature again, the relationship between color, environment and human behaviors were more complicated than anyone thought. Some said different outcomes came from different genders and ages (Stappenbeld, 2012; McInnis \& Shearer, 1964) and too many variables could be found in a situation (Whitfield and Whitshire, 1990). It was hard to state that color preference was or was not affected by genders, ages or other factors. Although most research proved that colors, environment affect appetite sensation could, the theory of personal background (gender and age) difference on color preference had not been confirmed. Perhaps, just like Acking and Küller (1972) stated that personal evaluation of colors was different to each individual. It was "personal difference".

\section{Limitation \& Furture Study}

Given the limited literatures and research related to the relationship between color in dining environment and appetite sensation, the findings of this exploratory study could provide rich information to guide future research studies. Thus, this study suggested direction for further investigation on this topic.

\section{A. Larger Sample Size}

When planning and organizing a research study, it is impossible and impartial to collect data from all people. Since this research study was an exploratory study, 50 undergraduate students were invited as subjects. Thus, the extension of applicability of the major findings is limited. To increase representation of the population and accuracy of major findings, a larger sample size is recommended.

\section{B. Use of virtual reality (VR)}

VR represents the possibility of creating different kinds of "sense of presence" to people. In addition, it provides a wider imagination of "environment". VR can lower the costs and restraint of a research study. It is not mere a dynamic internal simulation, but subjects can experience as if they 
Proc. of The Eighth Intl. Conf. On Advances In Economics, Social Science and Human Behaviour Study - ESSHBS 2018 Copyright (c) Institute of Research Engineers and Doctors, USA. All rights reserved.

ISBN: 978-1-63248-156-6 doi: 10.15224/978-1-63248-156-6-17

direct and immediate interact with something "real" (Westerhoff, 2015).

However, researchers need to consider ethical questions before using VR as a tool. Some subjects of this research study reported that they felt a little uncomfortable because of motion sickness, even though the process had followed the principle of non-maleficence for ethical reason. User must be made aware that there is limitation of simulated environment in further studies (Behr et al., 2005).

\section{Other Color Models}

In current study, eight colors were selected based on the definition of the HSV color model. Technically, there were other ways to select colors which should be examined in a study. Al-Rasheed (2015) selected eight colors by adjusting the hue angle, while Söker (2009) picked eight colors based on color perception of Turkish people (Şahin, 1998). Future studies of using differenct color were recommended, while researchers should clarify which color space they are studying in.

\section{References}

Acking, C. A., \& Kuller, R. (1979). The perception of an interior as a function of its color. Ergonomics, 15(6), 645-654

Al-Rasheed, A. S. (2015). An experimental study of gender and cultural differences in hue preference. Frontiers in psychology, 6, 30.

Aslam, M. M. (2006). Are you selling the right colour? A cross- cultural review of colour as a marketing cue. Journal of Marketing Communications, 12(1), 15-30.

Behr, K.-M., Nosper, A., Klimmt, C., and Hartmann, T. (2005). Some practical considerations of ethical issues in VR research. Presence, 14(6), 668-676.

Bellizzi, J. A., Crowley, A. E., \& Hasty, R. W. (1983). The effects of color in store design. Journal of retailing.

Birren, F. (1950). Color Psychology and Color Therapy. New York: McGraw-Hill.

Birren, F. (1963). Appetite appeal to food service. Color for interiors, historical and modern: An essential reference work covering the major period styles of history and including modern palettes for the authentic decoration of homes, institutional and commercial interiors (pp. 186-195). New York: Whitney Library of Design.

Donovan, R. J., Rossiter, J. R., Marcoolyn, G., \& Nesdale, A. (1994). Store Atmosphere and Purchasing Behavior. Journal of Retailing, 70(3), 283-294.

Guilford, J. P., \& Smith, P. C. (1959). A system of color preferences. The American Journal of Psychology, 73(4), 487-502.

Hunt, R. W. G. (2004). The Reproduction of Colour (6th ed.). Chichester UK: Wiley-IS\&T Series in Imaging Science and Technology.

Ishihara, S. (1975). Ishihara's test for colour-blindness. Japan: Kanehara Medical Publishing Co.Ltd.

Jalil, N. A., Yunus, R. M., \& Said, N. S. (2012). Environmental Colour Impact Upon Human Behaviour: A Review. Procedia-Social and Behavioral Sciences, 35, 54-62.

Kotler, P. (1973). Atmospherics as a Marketing Tool. Journal of Retailing, 49(4), 48-64.

Lowe, M. R., \& Butryn, M. L. (2007). Hedonic hunger: a new dimension of appetite?. Physiology \& behavior, 91(4), 432-439.

Magoulas, C. (2009). How Color affects Food Choices. UNLV Theses, Dissertations, Professional Papers, and Capstones. 552.

Mahnke, F. H., \& Mahnke, R. H. (1947). Color and light in man-made environments. New York: Van Nostrand Reinhold Company.

Maslow, A. H. (1943). A Theory of Human Motivation. Psychological Review, 50(4), 370.

McInnis, J. H., \& Shearer, J. K. (1964). Relationship between color choices and selected preferences for the individual. Journal of Home Economics, 56, 181-187.
Mehrabian, A., \& Russell, J. A. (1974). An Approach to Environmental Psychology. Cambridge, MA: MIT Press.

Robert, D., \& John, R. (1982). Store Atmosphere: An Environmental Psychology Approach. Journal of Retailing, 58(1), 34-57.

Ryu, K., \& Han, H. (2011). New or Repeat Customers: How Does Physical Environment Influence their Restaurant Experience?. International Journal of Hospitality Management, 30(3), 599-611.

Şahin, E. (1998) Color naming. Unpublished Ph.D. thesis. Bilkent University: Ankara.

Satter, E. (2007). Hierarchy of food needs. Journal of nutrition education and behavior, 39(5), 187-188

Sherman, E., Mathur, A., \& Smith, R. B. (1997). Store Environment and Consumer Purchase Behavior: Mediating Role of Consumer Emotions. Psychology and Marketing, 14(4), 361-378.

Söker, M. B. (2009). The Role of Color on the Assessment of Retail Space: Restaurant Atmospherics. Doctoral Dissertation, Bilkent University.

Stappenbeld, M. (2012). The Effect of Colour and Density on The Store Perception. Master's thesis, University of Twente.

Tam, S. M. (1997). Eating Metropolitaneity: Hong Kong Identity in Yumcha. The Australian Journal of Anthropology, 8(1), 291-306.

Valdez, P. \& Mehrabian, A. (1994). Effects of Color on Emotions. Journal of Experimental Psychology: General, 123(4), 394-409.

Whitfield, T. A., \& Slatter, P. E. (1978). The evaluation of architectural interior colour as a function of style of furnishings: Categorization effects. Scandinavian Journal of Psychology, 19, 251-255.

Whitfield, T. W., \& Whiltshire, T. J. (1990). Color psychology: a critical review. Genetic, Social, and General Psychology Monographs, $116(4), 385$

Winkielman, P., Schwarz, N., Reber, R., \& Fazendeiro, T. A. (2000). Affective and Cognitive Consequences of Visual Fluency: When Seeing is Easy on the Mind. Visual Persuasion. 